\title{
O LOCAL E AS EMOÇÕES SUSCITADAS: EXPERIÊNCIA ESTÉTICA NO IMAGINÁRIO URBANO DE TUBARÃO, SANTA CATARINA ${ }^{1}$
}

\author{
THE PLACE AND THE EMOTIONS RAISED: AESTHETIC \\ EXPERIENCE IN THE URBAN IMAGINARY OF TUBARÃO, SANTA \\ CATARINA
}

\author{
Deloisa Juncklaus Preis Moraes \\ Doutora, Universidade do Sul de Santa Catarina - UNISUL \\ Tubarão, Santa Catarina - Brasil. \\ heloisapreis@hotmail.com \\ Ana Caroline Voltolini Fernandes \\ Mestre, Universidade do Sul de Santa Catarina - UNISUL \\ Tubarão, Santa Catarina - Brasil \\ ana.voltolini@hotmail.com
}

\begin{abstract}
Resumo: Este artigo analisa, a partir do projeto municipal Domingo na Rua, os deslocamentos que estetizam as múltiplas interações com a cidade e sua condição pública, em função das diferentes lógicas de relação com os espaços. Assim, descrevemos a percepção da cidade a partir da experiência de sua apreciação estética, reconhecendo marcas das interpretações das dinâmicas culturais, sociais e ambientais em um exercício de etnografia de rua (ROCHA e ECKERT, 2013). Buscamos perceber se as pessoas que são atraídas pela experiência estética do fechamento da rua percebem a cidade de maneira diferente, expressando a alteração de sentido e simbolização da cidade, já que a rua deixa de ter um fluxo funcional, de comércio e trânsito, para permitir um lugar de vivência popular e integradora do imaginário da cidade. Em última análise, essa passa a ser uma experiência que forja o imaginário urbano, visto que se configura uma prática de educar para a imaginação (contato com a natureza, espaço público de lazer, relações sociais, atividades ao ar livre).
\end{abstract}

Palavras-chave: Estética. Imaginário urbano. Domingo na rua. Imaginação. Sensível.

Abstract: This article analyzes, from the municipal project, Domingo na Rua, the movements that occur as multiple interactions with the city and its public condition, in terms of the different logics of relationship with spaces. Thus, describing a perception of the city from the experience of its aesthetics, recognizing marks of the interpretations of cultural, social and environmental dynamics in an exercise of street ethnography (ROCHA and ECKERT, 2013). We seek to understand how people who are attracted by the aesthetic experience of closing the street perceive a city in a different way, expressing a change in meaning and symbolization of the city, since the street leaves a functional flow, commerce and traffic, to allow a place of popular experience and integrator of the city's imaginary. In the last analysis, this procedure becomes an experience that involves the urban imaginary and is a practice of education for the imagination (contact with nature, public leisure space, social relations, outdoor activities).

Keywords: Aesthetics. Urban imaginary. Sunday on the street. Imagination. sensitive.

\section{Para citar - (ABNT NBR 6023:2018)}

MORAES, Heloisa Juncklaus Preis; FERNANDES, Ana Caroline Voltolini. O local e as emoções suscitadas: experiência estética no imaginário urbano de Tubarão, Santa Catarina. Eccos - Revista Cientifica, São Paulo, n. 53, p. 1-13, e16708, abr./jun. 2020. Disponível em:

https://doi.org/10.5585/eccos.n53.16708. 


\section{Introdução}

O imaginário tem uma função de mediação do homem com o mundo, organizadora da vida e fator de marcas de homogeneidade na representação. "As relações sociais, suas manifestações, artefatos e processos, são causa e efeito de dimensões imaginárias. Para além de uma mera representação imagética, o imaginário é uma atmosfera, arquetípica, atemporal e coletiva, que nutre o universo simbólico e mental dos indivíduos, estabelecendo vínculos" (MORAES; MÁXIMO, 2016, p. 182). O imaginário se expressa em sistemas e práticas simbólicas sobre os quais buscamos refletir, e as perspectivas da antropologia e da sociologia do imaginário têm se configurado como uma "razão sensível” (MAFFESOLI, 1996), teórica e metodológica, para as nossas questões de pesquisa, necessidade sentida quando tratamos dos estudos de linguagem e cultura (MORAES, 2016). A cidade é local das relações em que fenômenos e práticas do urbano podem ser percebidos a partir de narrativas do imaginário. Ao pensar no local, o narrador revê as coisas em si, mas, especialmente, o sentido que as forma. E, a partir daí, podemos perceber que tipo de relação estabelece com o lugar. Os símbolos trazem a cidade à memória e estabelecem vínculo de pertencimento; já a construção simbólica das formas de expressão parece nos levar a uma matriz imaginária ligada ao consumo e ao lazer. Assim, diferentes grupos têm experiências e práticas cotidianas que expressam sua relação com a cidade.

Podemos perceber, então, que os moradores de Tubarão, sul de Santa Catarina, têm histórias afetivas de pertença territorial, ora pela simbologia da enchente que assolou a cidade, em 1974 (MORAES; MÁXIMO, 2016, MORAES; BRESSAN JR.; BRESSAN, 2019), ora pela identificação de símbolos ligados ao consumo e ao lazer em detrimento dos naturais. Isso reflete que há diferentes lógicas de relação com os espaços da cidade e, um símbolo, como o rio, pode ter sua carga semântica modificada. No caso do rio Tubarão, sua força está ligada ao mitema enchente e não à sua potência de natureza.

Esse exercício de narrar os usos da cidade, as formas de adesão aos espaços de socialidade, narrando o seu cotidiano, é investigar o imaginário, pois todas essas ações vêm carregadas de sentido. Àquilo que se dá sentido potencializa as motivações. Logo, ao pensar nas estruturas sensíveis do imaginário como acesso às práticas cotidianas (e vice-versa), podemos propor ações de eficiência ao desenvolvimento local. Ferreira-Santos (2011, p. 10) enfatiza, seguindo a linha teórica de Bachelard e Durand, que "[...] não devemos ceder ao caráter estático da classificação das imagens pela sua forma; mas, em seu 'estruturalismo 
figurativo', partir da 'figuração', para poder configurar e, numa fantástica transcendental, poder "transfigurar"'.

Desse modo, propomos, aqui, relatar a percepção da cidade a partir da experiência de sua apreciação estética, reconhecendo marcas das interpretações das dinâmicas culturais, sociais e ambientais em um exercício de etnografia de rua pelos usuários do Projeto Domingo na Rua, em Tubarão, Santa Catarina. Nossa experiência buscou analisar se as pessoas que são atraídas pela experiência estética do fechamento da rua percebem a cidade de maneira diferente, expressando a alteração de sentido e simbolização da cidade; identificar se os participantes do projeto Domingo na Rua revitalizam o imaginário urbano e sua relação com a cidade; verificar quais imagens e símbolos estruturam o imaginário urbano e permitem o reforço da identidade local.

Assim, falamos de um imaginário a partir do campo do sensível, percebendo a alma da cidade e fazendo relações com imagens míticas, como Hermes e Héstia, para refletir sobre a experiência estética vivenciada.

\section{Imaginário e sociedade}

Pensar o imaginário como uma matriz que organiza o social é concebê-lo como fator de homogeneização e congregação social. Isso porque é a partir da troca de experiências, do partilhamento do sensível, que o social ganha relevo e torna possível a vida em comum. Mafesolli (2014) nos informa que o desencantamento do mundo e a depressão que sonda a coletividade é resultado de uma degeneração estética, por assim dizer, que banaliza o cotidiano e despreza os aspectos sensíveis que, dele, emanam. Para o mencionado autor, deve-se ouvir o inaudível, ver o invisível e sentir o evanescente. Somente por meio de uma ciência que não exclua o sensível inerente ao convívio social é que se faz possível conceber o real em sua globalidade. O cotidiano, por exemplo, é terra fértil para ser pesquisado, pois, dele, emanam as ações sociais e demonstram o imaginário de uma localidade, uma cidade ou civilização. Nesse teor, segundo Teves (2002),

O cotidiano vivido - presente ou passado - sintetiza o processo dialético de atividades humanas, exercícios na sua objetivação, na sua complexidade. Daí se pode dizer que o entendimento da sociedade, sua reconstrução textual, a demanda da apreensão de sua ordem constitutiva, é ela que informa sobre sua organização e seu funcionamento. [...] Apreender uma realidade significa investigar sua dupla dimensão objetiva e subjetiva, e que se incorpora na ação coletiva dos membros do grupo (TEVES, 2002, p. 63). 
Nesse contexto, Moraes (2016) afirma que as manifestações do dia a dia, que emanam do cotidiano, revelam emoções coletivas, bem como demonstram o estar junto e as marcas de uma época. Ademais, o Imaginário manifesta-se por meio de tais expressões simbólicas e, para apreendê-lo, é necessário um olhar estético voltado ao sensível. Segundo Wunenburguer (2003, p. 317), “[...] o imaginário pode se tornar para o homem individual e para a sociedade uma verdadeira fonte psíquica, porque é um mundo que pode se desvelar à medida que entramos nele." O Imaginário é obra, portanto, de um reservatório tanto individual quanto coletivo e, para Maffesoli (apud SILVIO et al., 2014), existe uma espécie de cortina entre o real e o imaginário, que não se consegue ver, mas é passível de senti-la. Para o mencionado autor, o Imaginário seria uma força, uma espécie de amálgama que permeia as relações tribais e que se torna fonte comum de emoções, lembranças, afetos, estilos de vida, transformando-se um patrimônio compartilhado pela humanidade e, ao mesmo tempo, responsável por torná-la coesa.

Ferreira-Santos e Almeida (2012) aduzem que o dia a dia é uma abertura para se pesquisar o social, em razão da vida cotidiana ser a sutura entre natureza e cultura. Da mesma maneira, segundo os referidos autores, embora o cotidiano seja comumente associado ao repetitivo, idêntico e ordinário, é nele que o tecido social se desenvolve e manifesta o Imaginário. Isso porque a convivência com o Outro nos situa no mundo cultural por meio da circulação de bens simbólicos e da atribuição de sentidos para nossas existências e nossos hábitos (FERREIRA-SANTOS; ALMEIDA, 2012). Para Maffesoli (1995), as emoções individuais só adquirem relevo quando são alcançadas junto ao seio coletivo, sendo na nobreza da vida cotidiana, a partir daquilo que aparentemente é "comum", que se elabora um conhecimento do social:

Rede sutil, complexa, na qual cada elemento, objeto, assunto, situações anódinas,
eventos importantes, pensamento, ação, relações, etc., só funciona. enquanto ligado
ao todo e só faz sentido dentro e pela globalidade. É isso que se percebe, de uma
maneira mais ou menos consciente, na valorização contemporânea do quotidiano.
Sente-se em correspondência com os outros, participa-se, com os outros, de um
conjunto mais vasto. Todas as diversas massificações, as emoções coletivas, as
diversas efervescências festivas, as atrações tribais e outras modas de vestir, de
linguagem e de gestos nada mais fazem do que indicar, no quotidiano, a pregnância
de um estilo de vida ao qual a pessoa não pode escapar. O contágio está na ordem do
dia (MAFFESOLI, 1995, p. 65-66).

Podemos dizer que o imaginário medeia as relações humanas, dá sentido às ações sociais e conforma toda narrativa, agrupamento humano e manifestação social. Para Wunenburger (2007), o imaginário não satisfaz somente à sensibilidade humana, mas dá carga valorativa, fundamentos e fins a todas as ações sociais. Conforme suas palavras: “[ [...] o que, com efeito, incita os homens a agir socialmente, a obedecer, a respeitar as autoridades, as normas e as leis, 
a orientar seus desejos?”. Sironneau (2003) explica que os indivíduos são impelidos por forças sociais que os transcendem, por meio de estruturas que já existiam antes deles, e todas as ações sociais são simbólicas pelo fato de serem orientadas por intenções que remetem a um conjunto de regras, normas e valores, responsáveis por gerar e orientar a cultura. Nesse teor, Sironneau esclarece:

Um simbolismo constituinte que, antes de mais, significa que toda ação social, estruturada pelas regras da troca recíproca, é inevitavelmente significante e simbólica: aquilo que os homens trocam, além de bens e mulheres, são essencialmente sinais. Este simbolismo é inerente à ação e só a poderei compreender enquanto actor ou espectador, se puder substituí-la no conjunto das regras, convenções, crenças, que compõem uma cultura: somente a posse deste código cultural me permite apreender o sentido desta ou daquela ação (SIRONNEAU, 2003, p. 224).

Nessa esfera, Maffesoli (2014) expõe que o imaginário de um grupo pode ser observado em diversos contextos, tais como nas tendências da moda, no mimetismo social e no gregarismo cotidiano, comportamentos, estes, que enfatizam o sentimento de pertença. Ademais, o fenômeno social, segundo o autor, ocorre por meio do "juntar-se, reunir-se, assemelhar-se", de maneira que são as relações e as emoções que advêm destas mesmas interações que regem, atualmente, as vivências sociais. O Imaginário social, nessas circunstâncias, mostra-se em todos os objetos que nos envolvem, em nossos encontros ocasionais e nas distrações sociais. Sansot (apud SIRONNEAU, 2003) explica que o Imaginário intervém de forma positiva na vida cotidiana, exercendo, por assim dizer, um papel constituinte na medida em que é um mundo de imagens, de formas sensíveis, de sons e cores que transfiguramos por meio de uma sublimação estética. É nesse campo que o imaginário atua unindo o visível e o invisível:

\footnotetext{
Enquanto sistema simbólico, o Imaginário Social reflete práticas sociais em que se dialetizam processos de entendimento e de fabulação de crenças e ritualizações. Produções de sentidos que se consolidam na sociedade, permitindo a regulação de comportamentos, de identificação, de distribuição de papéis sociais. Trata-se de um campo de investigação recentemente autorizado que considera, como de igual valor, as funções do irreal e do real. Constituído de narrativas míticas, religiosas e ideológicas, o imaginário é um campo simbólico. Acessá-lo significa adentrar pelas vias sinuosas da linguagem em que metáforas, metonímias, alegorias, símbolos, signos não indissociáveis na sua instituição mesma (TEVES, 2002, p. 64).
}

O nível simbólico de dado tempo e espaço é possível de ser desvelado por meio das práticas que consolidam o estar junto e consubstancializam o sentimento de pertença. Para Maffesoli (1995), as práticas individuais e coletivas, as atitudes emocionais, as maneiras de pensar e de agir, em suma, todas as relações com o outro, são manifestações que permitem definir uma cultura. Essas visões do mundo, muitas vezes inconsciente e não percebida, são amplamente vivenciadas na vida de todos os dias. O imaginário de um indivíduo está, assim, enraizado em uma bio-história particular, por meio do temperamento, carácter, estrutura 
pulsional e fantasias arcaicas, mas este mesmo imaginário particularizado é impulsionado a se expandir e se renovar por meio de processos simbólicos que o fazem interagir com a totalidade do mundo, com a natureza e a cultura. $\mathrm{O}$ imaginário individual procura, assim, inscrever-se e apoiar-se em uma imaginário coletivo que, por sua vez, renova-se e se alimenta das produções individuais (WUNENBURGUER, 2003). Nesse sentido, segundo Teves,

\begin{abstract}
O Imaginário Social não é, pois, reflexo da realidade: é seu fragmento. Como uma amálgama, ele institui histórica e culturalmente o conjunto de interpretações, das experiências individuais, vividas e construídas coletivamente. Essa rede de sentidos matricia, sob diversos aspectos, a conduta coletiva na medida em que valores, normas e interdições, como códigos coletivos, são internalizados, apropriados pelos agentes sociais. [...] Investigar o Imaginário Social de um grupo é estar propenso a dialogar com seu mistério, com suas crenças mais profundas. Metaforicamente, podemos dizer que o imaginário é o locus no qual se ancoram as representações sociais (TEVES, 2002, p. 66-67).
\end{abstract}

Maffesoli (1996;2005) menciona que há uma potência capaz de transcender o indivíduo, que o faz membro de um genius coletivo e que contribui para a criação de seus meios natural e social. É essa força vital indiferenciada que se configura o fundamento de todo estar-junto. A estética, para o autor, não se limita ao âmbito da arte, mas está impregnada no conjunto da vida cotidiana e ganha grande relevo no imaginário contemporâneo. Ela designa a interação constante entre os indivíduos, que é diferente daquela que existia em outros séculos, na medida em que não é direcionada, não tem projetos e se contenta em vivenciar o dia a dia, no prazer da vida em comum. Nada individualizada, a estética constitui para o autor uma massa global que, de maneira orgânica, os elementos materiais e espirituais da vida social e natural entram em uma constante sinergia. Silva (2017) menciona que o caminho do imaginário é um trajeto de sensações, experiências, vivências, emoções, paixões, grandes medos, aventuras, traumas e sentimentos mais intensos e significativos, impressos no corpo e na alma de cada um, e, de acordo com nossos estudos, podemos estender esses mesmos elementos sutis aos âmbitos social e coletivo.

Scanducci e Freitas (2015, p. 49) enfatizam que o lugar, a cidade, a beleza são habitações da alma, visto que, esta, “[...] não é substância, mas relação, pois alma está em como se olha, e não naquilo que se vê”. Assim, destacam os autores, que o comum pode ser visto poeticamente quando o sentimento de pertença pede uma estética que colabore e toque a alma. Dessa forma, os espaços das cidades podem trazer impressões diferentes de sua vocação original, tal como percebemos no projeto analisado e veremos a seguir. 


\section{Etnografia de Rua}

O projeto Domingo na Rua, desenvolvido pela Prefeitura Municipal de Tubarão, desde 2017, consiste em fechar para trânsito automotivo a rua beira-rio aos domingos, convertendo-a em espaço de lazer. De segunda a sábado, a avenida tem o caráter comercial, ganhando nova vocação aos domingos. Nesse sentido, nossa intenção é apresentar um relato de investigação sobre a experiência estética vivenciada e compartilhada pelos usuários do projeto, discutindo um imaginário urbano e as diferentes paisagens de um mesmo espaço suscitadas enquanto imagem.

A pesquisa tem como base a perspectiva da Etnografia de Rua, cujos estudos estão fundamentados na antropologia urbana. A metodologia parte da premissa de que "[...] a cidade dos seus habitantes não é evidente e previsível, pois é no movimento das narrativas que ela se configura. Seus espaços de referência e de conexão se revelam em imagens da memória narrada" (ROCHA e ECKERT, 2013, p. 11) que é tecida no social, pois é sempre coletiva.

Assim, conhecer a paisagem urbana, suas vivências, seus usos e suas representações requer uma prática de intimidade: uma relação de adentramento do pesquisador na ambiência onde estão sendo construídas as relações com a cidade. Neste projeto em específico, ao propor descrever a percepção da cidade a partir da experiência da apreciação estética, reconhecendo marcas das interpretações das dinâmicas culturais, sociais e ambientais do Projeto Domingo na Rua, em Tubarão, Santa Catarina, analisamos a rua como lugar do vivido e do imaginado. Um lugar essencialmente de sensibilidades, memórias e afetos a partir das experiências, ali, vivenciadas. Para tanto, são necessárias a observação, conversação, anotações de registro, pelo paradigma estético, análise das figurações da vida social, tal como nos alertam as pesquisadoras: “[...] dedicar-se a uma etnografia de rua, [...] adotar um olhar sobre a cidade e sua vida cotidiana, voltando para as suas expressões sensíveis, na qual cada detalhe dessa vida da rua faz parte de um conjunto ao qual apresenta ao observador atento às imagens que a compõem" (ROCHA; ECKERT, 2013, p. 14).

Houve acompanhamento in loco de quatro domingos do projeto para entender a dinâmica das vivências e as suas formas de representação e sentido, utilizando-se dos recursos que permitam a descrição e narrativa desta experiência e sua relação com o imaginário urbano e a identidade local: anotação em diário de campo, entrevistas não-estruturadas (com os devidos Termo de Consentimento Livre e Esclarecido, como recomenda a CEP-Unisul), imagens, práticas desenvolvidas pelos cidadãos. Não houve critérios de exclusão para a participação 
como corpus de pesquisa, ao contrário, o único critério de participação foi vivenciar, de maneira espontânea, a opção da rua enquanto espaço de lazer.

Para a análise dos dados, utilizamos como método de análise a Sociologia Compreensiva que se preocupa com o que é, e não com o dever-ser. Esse paradigma busca compreender e explicar a dinâmica das relações sociais que, por sua vez, são depositárias de crenças, valores, atitudes e hábitos. Trabalham com a vivência, com a experiência, com a cotidianeidade e, também, com a compreensão das estruturas e instituições como resultados da ação humana objetivada. Ou seja, desse ponto de vista, a linguagem, as práticas e as coisas são inseparáveis (MINAYO, 1994, p. 24). O pesquisador passa a ser um mediador que dá voz ao social, às suas práticas, aos seus imaginários, e não aquele que explica e revela como deveria ser (SILVA, 2003, p. 80).

Maffesoli (1988), à procura do conhecimento comum, analisa e propõe a Sociologia (Compreensiva) via pesquisa estilística. É, nesse caso, o estilo do cotidiano que deve ser analisado, pois ele é feito de formas, palavras, teatralidade que nos dizem muito a respeito da existência. A trama social é polifônica e é preciso escutar e ver esses múltiplos sons, gestos e situações. É preciso respeitar a diversidade social. As exigências da pesquisa estilística, segundo o autor, são resistir aos discursos estereotipados e manter os pés na terra, visto que se trata de "[...]formas profundamente enraizadas nos modos de ser do povo" (1988, p.39). É deixar falar o estilo de vida, as manifestações sociais que dão forma à existência e à identificação do ser social. Entre o discurso e a ação, a socialidade possui um estilo, "[...] tratase desta teatralidade que constitui a trama da vida cotidiana" (MAFFESOLI, 1988, p. 39).

A teoria geral do imaginário foi desenvolvida para reforçar a retórica da imagem simbólica, destacando a dimensão dos arquétipos e a força diretiva dos mitos, estabelecida por meio de regras estruturais. Assim, a análise dos dados da etnografia de rua, realizada em quatro domingos, deu-se buscando a recorrência simbólica de imagens que traduzisse a experiência estética, simbolizasse o imaginário urbano e discutisse a identidade local. A Sociologia Compreensiva proposta por Michel Maffesoli em $O$ conhecimento comum (1988) amparou a proposição e análise de entrevistas com 14 pessoas que frequentaram o projeto analisado.

\section{Entre Hermes e Héstia}

Pitta (2015) enfatiza que tempo e espaço são noções imaginárias básicas de estruturação da cultura. Além de serem indissociáveis, são habitados por seres míticos. Buscamos dois desses seres para relacioná-los com a nossa pesquisa. Hermes e Héstia já tiveram sua 
simbologia ligada aos estudos da hospitalidade (DIAS; MOYA, 2015), o que faz pertinente sua relação simbólica com o espaço. Não há lugar sem ressonância arquetípica (SCANDIUCCI; FREITAS, 2015) e, no projeto analisado, esses deuses marcam presença em um mesmo lugar, mas em tempo diferente. Essa "disputa" simbólica marca a vocação, a dinâmica que dá forma (também simbólica) ao espaço. Ele, Hermes, "mensageiro dos deuses, deidade do comércio" e, ela, Héstia, “deusa do fogo doméstico” (BULFICH, 2013, p. 565); o caráter doméstico liga-a a um clima de fraternidade, intimidade, remetendo a um clima emocional, um campo de interações.

Com idades entre 20 e 45 anos, todas as entrevistadas eram do sexo feminino e a maioria frequentou o Domingo na Rua com a família, por isso, um dos pontos iniciais a serem ressaltados sobre o projeto foi a oportunidade que ele criou para a interação entre familiares e amigos em um ambiente fora do usual, incentivando as pessoas a irem para a rua. Outro ponto positivo destacado por todas as entrevistadas foi a segurança e sensação de liberdade que o projeto proporciona em uma área urbana sem muitas opções de lazer.

É interessante observar o consenso em todos os relatos a respeito da diferente percepção do espaço urbano nos dias de semana e no domingo, quando ocorre o projeto. Uma rua predominantemente comercial, com constante fluxo de carros e pedestres, ganha um novo aspecto quando é fechada para o entretenimento. A percepção do espaço é diferente para todas as entrevistadas. Além da liberdade, tranquilidade e segurança de poder usufruir e apreciar mais a cidade em que vivem, as entrevistadas também ressaltam a sensação de desfrutar de uma via pública. Eis a nossa relação com a simbologia de Hermes e Héstia. Durante a semana, o caráter comercial, de fluxo intenso, marca a relação de tempo e o espaço com ressonância em Hermes. Mas, aos domingos, com o comércio e rua fechados, essa relação é outra. O local se transforma em experiência, provoca aesthesis, mobiliza, congrega.

Podemos perceber uma aura no ambiente aos domingos: famílias brincando (bicicleta, bola, patins, patinete), passeio com pets, encontro de amigos, pessoas sentadas no meio-fio conversando, interagindo. Continuamente novos grupos e rodas de conversa se formando à medida que as pessoas iam caminhando e se encontrando. Essa aura sentida também foi relatada pelas entrevistas como clima, sensação, estado de espírito.

Scandiucci e Freitas (2015) destacam algumas características que confirmamos na experiência estética do imaginário urbano analisado: valorização do singular (cada domingo é único, pois proporciona uma experiência ímpar), personificações (cada um reporta a sua vivência e traz à tona suas memórias, conferindo sentido particular - ainda que sejam recorrentes no coletivo), bricolagem (cada um - ou família faz a sua própria vivência), 
intimidade com o ambiente (percepção da natureza, desfrute do ambiente como sentar-se à sombra para conversar), sentido público e coletivo (apropriação do local para uma experiência coletiva). Maffesoli (2014) nos fala de localismo afetual e é aí que nos repostamos à Héstia: “[...] muitas vezes percebida como o próprio lugar, Héstia congrega as pessoas e possibilita uma experiência anímica, um local vivo, onde há comunidade e comunhão" (FREITAS apud SCANDIUCCI; FREITAS, 2015, p. 50).

Estar ao ar livre, reunir a família e os amigos, ter a oportunidade de se conectar com outras pessoas é o que marca uma geração que rememora a infância que tinha a rua como palco de brincadeiras, imaginação e criatividade, e também encanta os mais novos, que passam a conhecer uma diversão além da virtual. Esse contato com a natureza e integração com o ambiente ao redor, descobrindo e redescobrindo alguns passatempos já esquecidos por causa da era digital, é uma das características mais apreciadas pelas entrevistadas. "As pessoas só se lembram de um espaço porque viveram nele emoções" (PITTA, 2015, p. 167).

É, pois, a dinâmica, a emoção, a afinidade, a experiência que dão forma ao espaço. Temos, pelos relatos e pela observação da dinâmica, uma paisagem formada pela experiência estética e transformada em imagem (recorrente coletivamente) no imaginário urbano. Não apenas uma imagem que se contempla, mas que se vivencia, experimenta. Há um partilhar de experiências, sentimentos, impressões e afetos que reforçam o coletivo e a alma do ambiente em um campo complexo de significados.

\section{Considerações finais}

Assim, percebe-se que os participantes do Projeto Domingo na Rua tiveram uma experiência estética diferente com a cidade de Tubarão. Em meio ao concreto de uma área urbana, o projeto destacou o verde e a natureza da cidade azul, suprindo a falta que o município tinha de um parque ambiental e despertando o interesse dos moradores para que pudessem apreciar e valorizar o ambiente natural da cidade. Dessa forma, o projeto consegue imprimir no imaginário dos tubaronenses uma nova forma de ver o lugar onde moram, mudando a percepção que muitos tinham desse espaço, promovendo uma experiência diferente com o espaço urbano, permitindo que, num dado espaço-tempo, uma nova relação com a cidade, com ritmos e imagens de identidade diferentes das habituais se estabeleça. As recorrências simbólicas giram em torno dos mitemas: segurança, contemplação, rememoração e sensação de liberdade. São eles, estes mitemas, que formam pontos de figuração (de intimidade, aconchego e acolhimento) 
do projeto que proporciona uma experiência estética diferente ao imaginário urbano local e fortalece laços de vínculo e pertencimento com a cidade.

A rua é o lugar de relações sociais, potencializada enquanto tal pela vocação temporalmente proporcionada, tornando-se espaço de apropriação, identificações, pertencimento e identidade. O que nos motiva é, pois, as dimensões sensível e simbólica, das quais decorrem a poética e as imagens - mobilizadoras de imaginários - do cotidiano. As formas do viver e do habitar ensejam o lúdico: divertimento e alegria - cultivo da afetividade, como bem destacam Saguimoto, Sandeville Jr. e Queiroga (2015), quando a rua ganha um ar de praça ou mesmo de quintal de casa. Neste momento, as pessoas se apropriaram simbolicamente da cidade. 


\footnotetext{
${ }^{1}$ Esta pesquisa teve a concessão de Bolsa pelo Programa Institucional de Bolsas de Iniciação Científica (PIBIC-Unisul), do Conselho Nacional de Desenvolvimento Científico e Tecnológico (CNPq).
}

\section{Referências}

BULFINCH, Thomas. O livro da mitologia: a idade da fábula. São Paulo: Martins Claret, 2013.

DIAS, C. M. DE M.; MOYA, I. M. DA S. Héstia \& Hermes - pesquisa e reflexões sobre o simbólico e a hospitalidade. Cadernos de Pedagogia Social, n. Especial, p. 99-117, 1 jan. 2015.

FERREIRA-SANTOS, Marcos. Prefácio. In: GOMES, Eunice Simões Lins (org.). Em busca do mito: a mitocrítica como método de investigação do imaginário. João Pessoa: Editora UFPB, 2011.

FERREIRA-SANTOS, Marcos; ALMEIDA, Rogério de. Aproximações ao imaginário: bússola de investigação poética. São Paulo: Képos, 2012

MAFFESOLI, Michel. O conhecimento comum: compêndio de Sociologia Compreensiva. São Paulo: Brasiliense, 1988.

MAFFESOLI, Michel. A contemplação do mundo. Porto Alegre: Artes e Ofícios, 1995.

MAFFESOLI, Michel. No fundo das aparências. Petrópolis: Vozes, 1996.

MAFFESOLI, Michel. A Transfiguração do Político: a tribalização do mundo. 3. ed. Porto Alegre: Sulina, 2005.

MAFFESOLI, Michel. Homo Eroticus. Rio de Janeiro: Forense Universitária, 2014.

MINAYO, Maria Cecília de Souza (org.) Pesquisa social: teoria, método e criatividade. 20. ed. Petrópolis: Vozes, 1994.

MORAES, H. J. P. (2016). Sob a perspectiva do imaginário: os mitos como categoria dos estudos da cultura e da mídia. In G. G. B. Flores, N. R. M. Neckel \& S. M. L. Gallo (orgs), Análise do Discurso em Rede: cultura e mídia, v. 2. Campinas: Pontes.

MORAES, Heloisa Juncklaus Preis; MÁXIMO, Willian Corrêa. Recorrências e convergências do imaginário: o dilúvio mítico como matriz imaginal de identidade local após uma enchente. Cadernos de Comununicação, Santa Maria, v.20, n.3, art 9, p.182-191, set/dez. 2016. Disponível em

file://C:/Users/Usuario/Downloads/22933-116948-1-PB.pdf. Acesso em 27 abr. 2018.

MORAES, Heloisa Juncklaus Preis; BRESSAN JR., Mário Abel; BRESSAN, Luiza Liene. Crônicas de um rio: a paisagem de um imaginário coletivo e imagens de memória.

Imagonautas. Revista Interdisciplinaria sobre Imaginarios Sociales. Vigo-ES, n.14, 2019, 
p.128-145. Disponível em

http://imagonautas.webs.uvigo.gal/index.php/imagonautas/article/view/182/145 .

Acesso em 26 fev. 2020.

PITTA, Danielle Perin Rocha. Adaptação do AT-9 (Yves Durand) à Arquitetura: para uma arquitetura sensível. In: RIBEIRO, Sandra M. P; ARAÚJO, Alberto Filipe. Paisagem, Imaginário e Narratividade. São Paulo: Zagodoni, 2015. p. 167-189.

ROCHA, Ana Luiza Carvalho da; ECKERT Cornelia. Etnografia de Rua: estudos de antropologia urbana. Porto Alegre: Editora da UFRGS, 2013.

SCANDIUCCI, Guilherme; FREITAS, Laura Villares de. A psique no espaço: pertinências e imaginação do/no lugar. In: RIBEIRO, Sandra M. P; ARAÚJO, Alberto Filipe. Paisagem, Imaginário e Narratividade. São Paulo: Zagodoni, 2015. p. 45-53.

SILVA, Juremir Machado da. As tecnologias do Imaginário. Porto Alegre: Sulina, 2003.

SILVA, Juremir Machado da. Diferença e descobrimento. O que é o imaginário? A hipótese do excedente de significação. Porto Alegre: Sulina, 2017.

SILVIO, Anaz. et al. Noções do Imaginário: perspectivas de Bachelard, Durand, Maffesoli e Corbin. Revista Nexi. São Paulo, v. 3, p. 1-16, 2014. Disponível em: < https://revistas.pucsp.br/nexi/article/view/16760>. Acesso em 25 jan. 2020.

SIRONNEAU, Jean-Pierre. Imaginário e sociologia. In: ARAUJO, Alberto Filipe;

BAPTISTA, Fernando Paulo. Variações sobre o imaginário: domínios, teorizações e práticas hermenêuticas. Lisboa: Instituto Piaget, 2003, p. 219-237.

SAGUIMOTO, Flávia Tiemi; SANDEVILLE JR., Euler; QUEIROGA, Eugênio Fernandes. A dimensão lúdica das paisagens partilhadas. In: RIBEIRO, Sandra M. P; ARAÚJO, Alberto Filipe. Paisagem, Imaginário e Narratividade. São Paulo: Zagodoni, 2015. p. 226-239.

TEVES, Nilda. Imaginário social, identidade e memória. In: FERREIRA, Lucia M. A e ORRICO, Evelyn G. D. (orgs.) Linguagem, Identidade e Memória Social: novas fronteiras, novas articulações. Rio de Janeiro: DP\&A, 2002.

WUNENBURGER, Jean-Jacques; ARAÚJO, Alberto Filipe. Introdução ao imaginário. In: ARAUJO, Alberto Filipe; BAPTISTA, Fernando Paulo. Variações sobre o imaginário: domínios, teorizações e práticas hermenêuticas. Lisboa: Instituto Piaget, 2003, p. 23-43.

WUNENBURGER, Jean-Jacques. O imaginário. São Paulo: Loyola, 2007. 